\title{
Engaging the Crowd:
}

\section{Lessons for Outreach and Tool Design From a Creative Online Participatory Study}

\author{
Johannes Mueller, ETH Zurich, Switzerland \& Future Cities Laboratory, Singapore-ETH Centre, Singapore \\ Shiho Asada, ETH Zurich, Switzerland \& Future Cities Laboratory, Singapore-ETH Centre, Singapore
}

Ludovica Tomarchio, ETH Zurich, Switzerland \& Future Cities Laboratory, Singapore-ETH Centre, Singapore

\begin{abstract}
In this article, the challenges of realising e-participatory projects in urban planning are described. A participatory case study in Singapore serves as the basis for their presented conclusions. The researchers used a map-based e-participation tool to collect design proposals from participants for the planning site. The user feedback for the tool interface and the study campaign's website together with designer expertise on user interfaces (UI) was incorporated into the redesign of the website and interface of the participatory design tool. From there, some general guidelines for conducting engagement studies and for designing participatory design tool interfaces for non-expert users were formulated. One key finding is that the information presented to the non-expert user must be concise, and the UI must be adapted to the user's habits and focus the user's attention towards completing the study.
\end{abstract}

\section{KEYWORDS}

Citizen Design Science, Creative Crowdsourcing, Participatory Design, Tool Design, User Interface Design

\section{INTRODUCTION}

Technologies that serve the public - known as civic technologies - have promised the inclusion of more citizen-inclusive planning strategies as part of urban governance. In the literature, these tools are usually considered for their functionality but not in the context of the entire participation process and interface design (Hasler et al., 2017). In this paper, we address the question of how to encourage citizens to use online participation tools and identify the level of willingness for citizens to use them. We describe the requirements for a good online participation platform and a user interface of the tool.

The case study that was carried out uses a map-based e-participation tool to collect design proposals which participants could create through an interactive user interface (Mueller et al., 2018). We describe how we engaged citizens to participate in a project where they used an online participatory design tool on a website and explain how the user interface (UI) of the website and the online participatory design tool was redesigned to improve the usability for users who are nonexperts, or who are not as digitally savvy. The tool is used in a government-to-citizen participation 
mode, albeit our aims are research-focused (Linders, 2012). We will describe the challenges of the outreach in that context rather than conducting a strict proof-of-concept analysis.

We begin by providing a short review of the modern concepts for participation in urban planning and look at existing principles for web and tool design. The following section describes and justifies the study design and the campaign website. We then introduce the functions of the online participatory design tool used during the study and describe the initial UI. The results contain user feedback on the website and tool, and the process used to redesign both interfaces. At the end of this paper, we generalise our findings by formulating guidelines for the design of participatory studies and the UI for participation tools in urban planning.

\section{LITERATURE REVIEW}

Citizen participation has been proven to be a feasible and an important instrument in the urban planning process. Creative and innovative approaches, in particular, tend to enhance community participation (Cilliers et al., 2011). The theory and practice of engagement tools for urban planning, such as workshops and town-hall meetings, have been broadly discussed among scholars (Wates, 2014; Nanz \& Leggewie, 2016) and the various forms of e-participation (Wilson et al., 2017; Kleinhans et al., 2015) and digital participatory tools have already been described in multiple studies. Most tools can be used for face-to-face and online participation and approaches have been developed in tandem with the use of such tools, which differ from traditional engagement methods. Stelzle and Noennig (2017) have developed a database of how tools have been implemented in the planning process. The typical categorisation of methods into information, consultation, collaboration and empowerment is based on Arnstein's ladder of participation (Arnstein, 1969). Our study uses a tool that consults citizens on their preferences for issues related to urban planning through micro-design tasks.

All participatory projects, regardless of the form or medium, must fulfil particular requirements for it to be considered a success. Stiftung Zukunft Berlin, the organisers of several participation projects in Berlin, have formulated five principles for satisfying participatory planning (Heuser et al., 2018):

1. The government and the citizens genuinely want civic co-responsibility;

2. It should be clear which parameters are negotiable;

3. The choice of representatives of each stakeholder must be justified;

4. The engagement process must be suitable and transparent and its management neutral;

5. Citizens need to stay involved after the engagement is finished.

If the engagement campaign is organised by an authority, the points 1,3 and 5 can be ensured. In our case, we can only guarantee the 2 nd and 4 th principles by communicating to participants the study process and programming building restrictions into the tool (E.g. The Urban Redevelopment Authority (URA) stipulates a maximum building height of 160 metres).

The fifth and final principle on the list should not be underestimated as it is critical for showing how impactful the decisions of the participants are. Being able to show immediate benefits has been proven to be helpful for increasing participation (Kersten et al., 2015). As participants will not directly benefit from their participation in such studies, it is important to inform them that they have a say, and that they can influence the project outcome. Keeping citizens updated post-engagement is therefore important to sustaining participant motivation.

Kahila-Tani et. al. (2016) and Brown (2014) used the five characteristics by Rowe and Fewer (2000) to assess their own PPGIS studies. One of their conclusions is that planners need more support in the design of a participation process. The description of best practices examples is suggested to support planners in practice (Kahila-Tani et al., 2016; Kahila, 2013). While in academia conducting outreach is usually not a priority and rarely discussed in the literature, it is essential to 
our participation study. As such, this article will focus on the study design and the outreach efforts to potential study participants.

Ensuring a high citizen participation rate has also been cited as a challenge (Münster et al., 2017). As digital participation tools aim to involve as many citizens as is practical, it is important to consider both the channels of communication by which people are informed of the participation project, and how the information is communicated to them. Besides providing information in a simple-to-understand, unbiased and transparent way (Levin et al., 1998), Münster et al. (2017) also recommend that the user interface be designed to meet the needs of all potential users, who may not all be digitally savvy.

Taking the above-mentioned research gaps and challenges, in this paper we address the following research questions:

RQ1: How do we encourage citizens to use online participation tools, bearing in mind that such tools are novel to citizens in the first place?

RQ2: How can a participation platform and the interface of an interactive map-based participatory design tool be designed to encourage meaningful citizen participation?

In our study, we use two web interfaces to communicate with study participants: the project website, and the online participatory design tool. The appearance of web content strongly influences the user's first impressions and subjective experience (Lindgard, et al. 2006). The layout is also important for gaining the trust of users (Karvonen, 2000). It is also observed that users will abandon the webpage once they feel frustrated or unsatisfied with the way the information is presented (Parush et al., 2005). According to Ginige and Murugesa's (2001) categories of web applications, the study website is informational, whereas the online design tool can be considered as a collaborative work environment. As it allows interaction between users just after the design process, it thus resembles mostly an interactive geo-information interface. Vincent et al. (2018) has shown that the UI has a significant influence on decision-making and the interface complexity is more important than the decision complexity. However, there is often a disconnect between what non-experts want and how current interaction systems are designed (Lee et al., 2017). In our approach we overcome this gap by incorporating user feedback into the first prototypes. A review of user interface design for web applications by Shamat et al. (2017) noted a few issues concerning the discussion on user interface designs. One problem is that there is a difficulty for comparing UIs as there is no specific way to document them (Hussey, 2000). Hence, a structured comparison between different interfaces is not possible, and the procedure of building user-friendly interfaces is non-linear (Terry \& Mynatt, 2002). Wenting et al. (2010) argue that users with different backgrounds process information in different ways which must be reflected in the design of the UI as well. These issues were also considered in the user-centred redesign of the web interface of the 3D modeller tool, later discussed in the paper.

We follow the concept of user-utility-usability as explained by Roth et al. (2015) and similarly described by Lukyanenko et al. (2016). We first reviewed the users' feedback and identified the difficulties users faced with the initial design. We then drew a storyboard based on a new userscenario. We ensured that the UI's layout was uncluttered, and that the fonts and colours used for the design were consistent. Finally, all the mock-ups were combined into an interactive prototype. To create an intuitive and user-friendly UI, the user experience design disciplines and processes are applied (McKay, 2013).

\section{STRATEGY AND DESCRIPTION}

The site of the case study is the current container terminal of Tanjong Pagar in Singapore. As the 4.5 sq. km large area will be planned for redevelopment after 2027, the Urban Redevelopment Authority 
(URA) is looking for suggestions for how the area could be redeveloped as part of their master planning exercise (URA, 2014).

We used the site to develop a participatory study and to test the online participation tool that we developed. There were, however, limitations in the impact of our study: as the results of the study were unpredictable, URA could not guarantee that the submitted design proposals would be taken into consideration during the master planning exercise. Furthermore, they did not provide details on the site's infrastructural restrictions, only sharing the maximum building height, and the minimum quota for built units and commercial areas. Given this, we decided the best way forward was to summarise the outcomes of the study once it was completed and brief the designers and planners of the authorities of the results.

The study design included three different ways of conducting public outreach: through pop-up events on the street, using social media, and conducting experiments with paid participants to gather detailed feedback on the tool's current level of usability, and suggestions for how to improve it. The face-to-face interaction with passers-by was useful not only as a way to introduce the tool prototype, but also to take videos that could be shared on social media in the second phase of the study. The first phase also helped to make smaller changes of the exercise and fix smaller bugs that were implemented in the exercises for the later stages.

For the second phase, we shared the study on social media, and with several local Facebook groups with members who could potentially be interested in participatory urban design. A local nongovernment organisation with experience in participatory design projects supported our outreach efforts by providing management support for the first two phases, and by helping to disseminate information about the study through their networks.

The landing homepage of our campaign was the central element for informing the public about the study. The project strategy included compiling all relevant data prior to making these accessible to them. On a subpage, an interested user could get more details on our design approach, the study and involved organisations.

The top element of the original website is a satellite image of the study area that was also shown on posters during the initial workshop. The row below contains three boxes showing the three different exercises we prepared for our tool. The links direct the user to the corresponding subpages, which explain the background of the exercises. From there, users would be directed to another tool where they would complete the design exercise. After submitting a design proposal, users are prompted to complete a questionnaire, where they can write down other ideas and wishes related to their submitted design.

After accessing the link to the exercise, a pop-up window containing information about how to use the tool appears. The tool is a 3D modeller that allows users to manipulate the position of objects on the $2 \mathrm{D}$ surface. The left mouse click is used to select, unselect and change the position of objects, while the right mouse click rotates an object. If no object is selected, holding the left and right mouse click will affect the view position or angle of perspective, respectively. These functions also work on touchscreens, but users use two fingers to right-click.

The tool is intended to provide citizens with an interactive, visual activity that allows them to participate in the engagement process as non-experts, rather than through traditional platforms like town hall meetings. It also aims to encourage user interventions through creative suggestions, although admittedly the creativity is restricted by the overall structure of the tool, and the user's design language is constrained the limited library of objects for each exercise.

Although this may seem restrictive, the limited parameters for creating design proposals allows the collected data to be evaluated more easily. That said, the design interface should be as intuitive as possible so that the users do not feel constrained when completing the exercise.

As abovementioned, the goal of the study to find out whether users are open to this new approach in citizen participation, and to streamline the user interface to improve the tool's usability. 
A screenshot of the original interface setup as displayed on a typical computer or tablets is shown in Figure 1. While the tool can be accessed on a mobile device, is not optimised for mobile devices due to the fixed size of some of the elements in the tool.

On the left, the user will see the main window of the modeller, the 3D viewer, and on the right the library of objects that the user can add to the main window (1). The library consists of the geometry and info tab (2). The info tab displays more information about the exercise, but if an object is selected, information about the object will be displayed. The buttons between the main viewer and the right panel (3) has several functions such as submitting a completed design or hiding the panel. Users can also be directed to other functions of the tool (e.g. gallery of other submissions) on the top left (4). Anonymous participation is enabled for the study.

Figure 1. (a) Ul of the original version of the participatory design tool as used during the study; (b) Interface of the tool on the device as used in the study

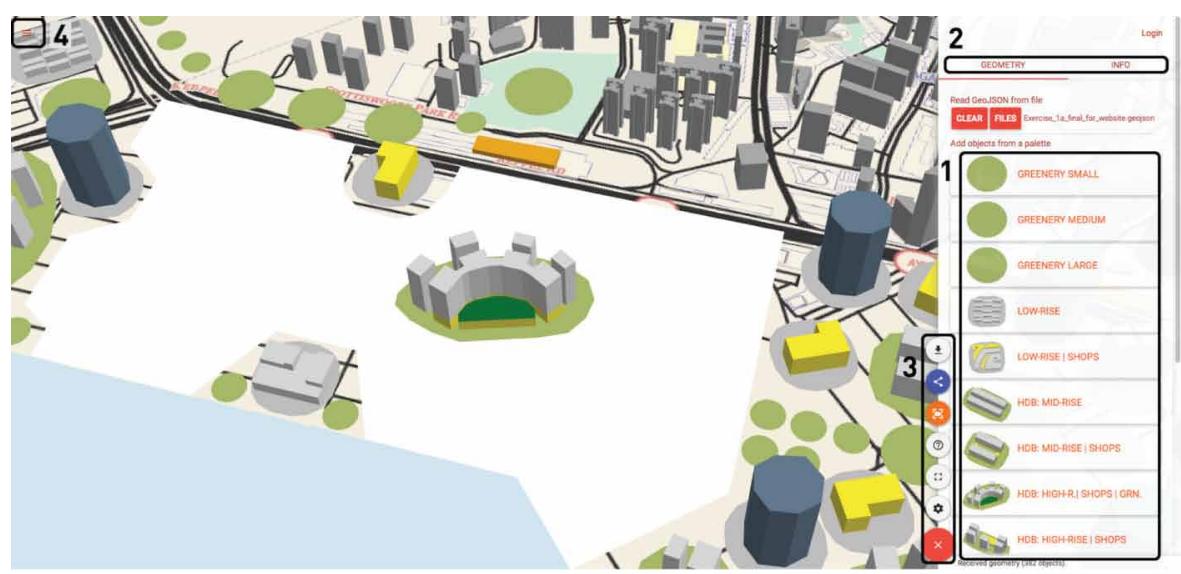

(a)

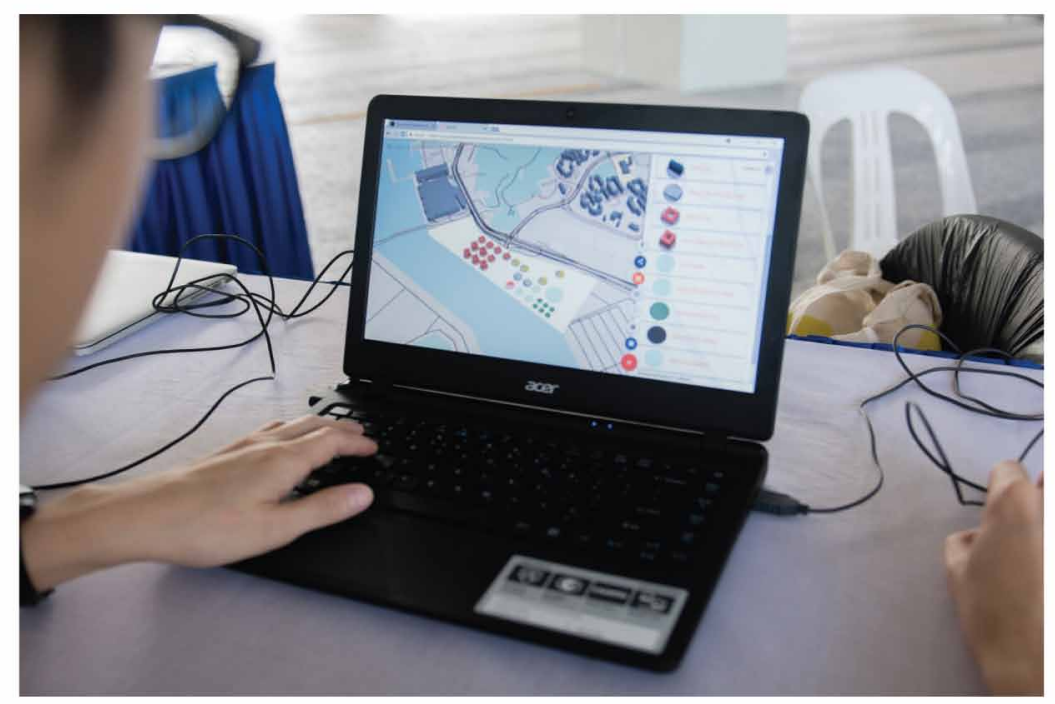

(b) 


\section{RESULTS}

\subsection{Feedback}

The study design turned out to be a good strategy for some parts. The participants of the street event generally agreed with the idea of creative participation in urban planning. The new technology of the interactive $3 \mathrm{D}$ viewer was also positively received as participants took more time than expected (around 20 minutes) to submit the design and fill out the survey. There were only minor technical problems with the computers during the event, and questions regarding the handling of the tools could be answered directly by the staff. The participants were mostly young (57\% between 20 and 25 years old, 17\% below 20 years old) and well-educated. That is not surprising as the workshop took place at the local university campus. The mix between gender was nearly equal with $55 \%$ male participants. Also, in the online study, the majority of participants (around 65\%) were below 30 years old.

A larger problem faced was the dissemination of the study online. While the video shared on social media garnered attention, the overall click-through rate was only at around $1 \%$. Although this is not an uncommon phenomenon in the web (Arthur, 2006), it was lower than expected. We also received feedback that the website was perceived to be academic in tone, and that users would have preferred to be immediately directed to the tool instead of reading through preliminary background information about the study and the exercises.

Another problem we faced was that the impact of the study was unknown. As we could not guarantee that the authorities would take the study's findings into consideration when making planning decisions, the project was perceived as a scientific study instead of a participation campaign with tangible outcomes. Furthermore, because the second phase of the study was online-only without any on-site events, users may have been not as motivated to complete and submit their design proposals.

It was also challenging to gather interest in the topic, as the redevelopment of Tanjong Pagar, planned for 2027, was not directly related to the daily lives of citizens. On social media, only three Facebook groups allowed us to post the link to our website. We also did not anticipate that social media is often accessed on mobile devices in Singapore. As such, user who accessed the tool via a social media link faced technical problems as the tool's design was not optimised for mobile devices.

We observed five UI difficulties that users experienced frequently. For the handling of the tool, users tried to drag and drop objects from the object palette at the side. Users also did not use the rightclick function to rotate objects or change the angle of perspective as the right-click function is not typically used in browser applications. There were also issues with how information was presented. Participants struggled to find the button to submit their design proposal, and hardly checked the info tab as a click on the tab hides the object palette. Some participants also wanted more guidance for using the tool and suggested creating a walk-through guide with short pop-up notes for first time visitors.

From these observations, we realised that the requirements for a tool's user-friendliness is very high as people are used to work with apps and websites that fit their online habits. Despite the limitations of the tool, however, the majority of participants agreed that they would be interested to participate in similar studies, enjoyed the design exercise, and confirmed that the exercises were easy to do (Figure 2). Most participants understood the instructions accompanying the exercises and found the tool interface intuitive. One perceived drawback for the tool was that the design language was restricted by the objects and exercises. Although there was a text field for open-ended responses that users could write in when submitting the design proposal, not everyone perceived that the design tool allowed enough freedom for expressing their ideas.

Another general observation was that users who attended the workshop or the experiment rated the tool more positively than those who had no prior contact with any of the study staff. This may indicate that the website and tool can be made more self-explanatory.

From the feedback received, we changed the layout of the campaign's homepage, and subsequently redesigned the UI, with assistance from an expert in interaction design. We will present and explain the redesign of the website and tool in the following section. 
Figure 2. Summary of one part of the user feedback for the tool. Answers are in percentage, experiment: $n=65$, workshop: $n=49$, online: $n=21$. The darker the bar, the more positive is the feedback.

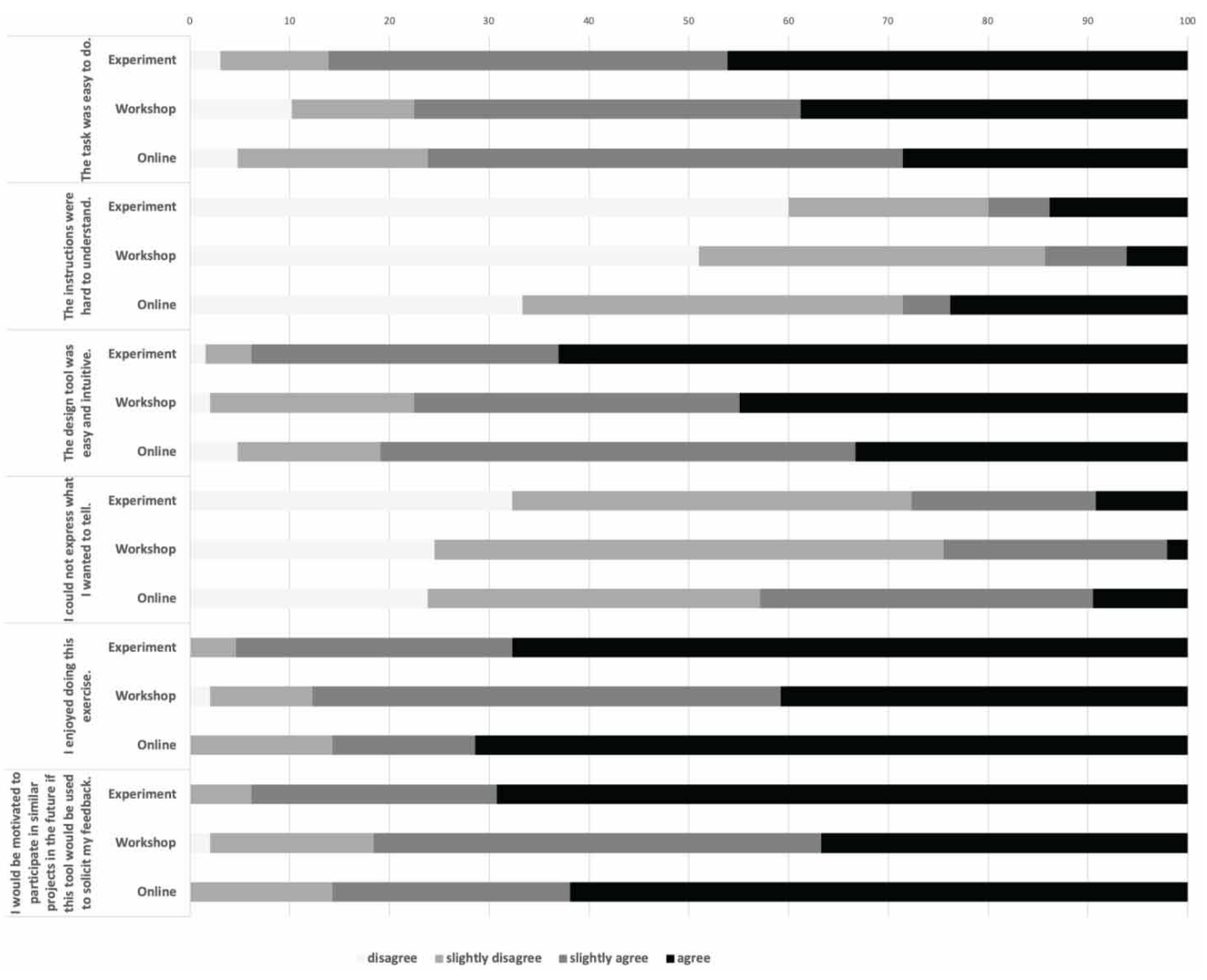

\subsection{Redesign}

\subsubsection{Website}

As it was observed by users that the tool could not be immediately accessed from the homepage, we made the links to the exercises accessible on the main page (Figure 3). We also included a 'read more' link to the subpages for participants who wanted more information on the study. We reduced the height of the main picture so that there was less text to scroll down. We also included a gif animation showing screenshots of the tools and brief instructions for how to use the tools on top of the links to the exercises. These changes allowed users to quickly form an impression of the study just by accessing the homepage. Lee and Benbasat (2003) showed that motion on a dynamic web interface gets higher attention by users than a static one.

\subsubsection{Tool}

The redesign of the tool could not be implemented in the study as it requires fundamental changes to the UI. As such, the description of the update refers to a mock-up created by a UI designer, which incorporates the feedback received from the participants.

One fundamental change in the layout is how the space is organised (Figure 4). The object palette has been moved to the top left (1), and the info table, as an optional window, to the bottom left (2). An additional window for analysis and statistics is located on the top right (3), and the taskbar has been moved to the bottom right. The website has a responsive design with relative instead of absolute 
Figure 3. Structure of the updated study website
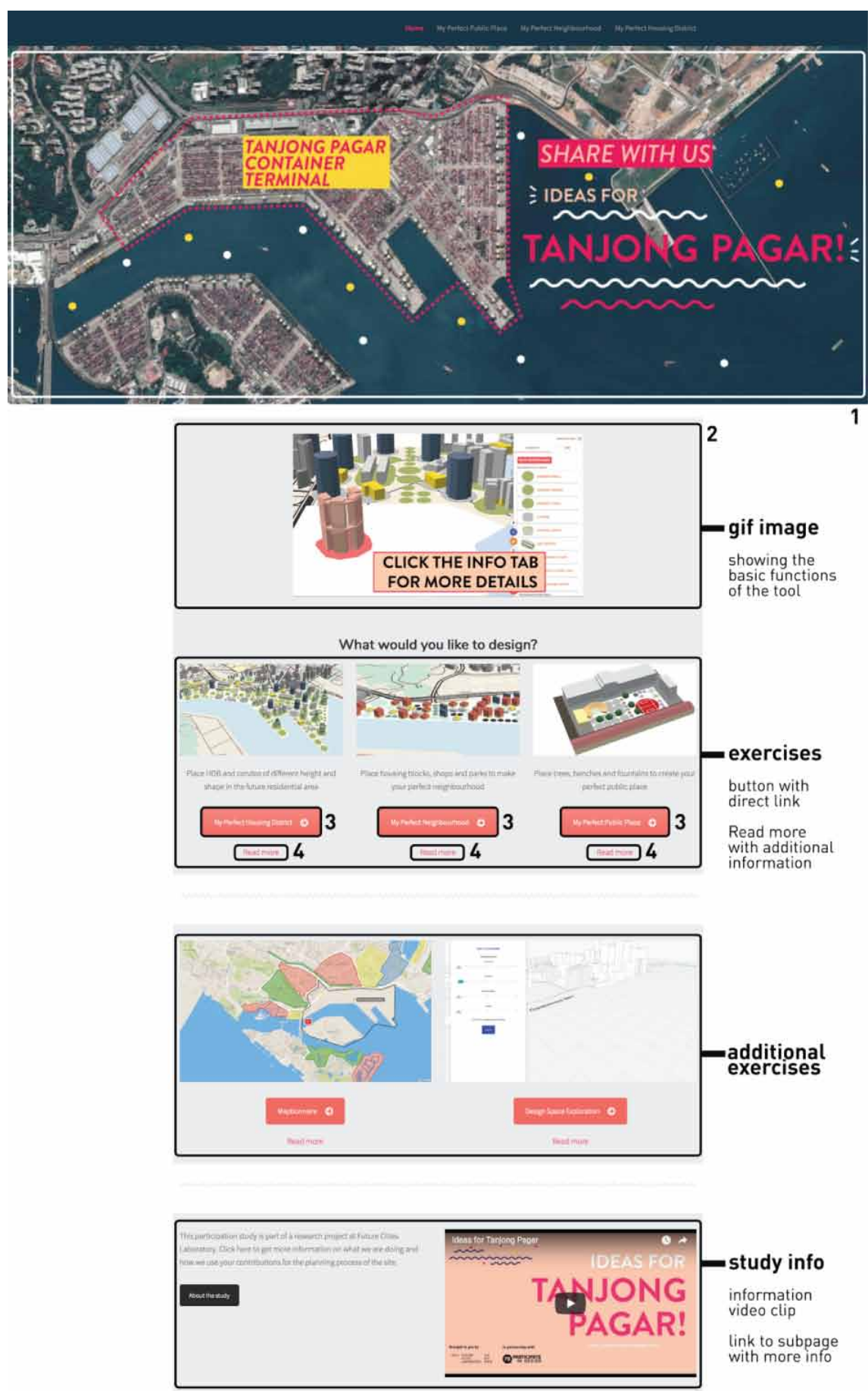

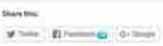




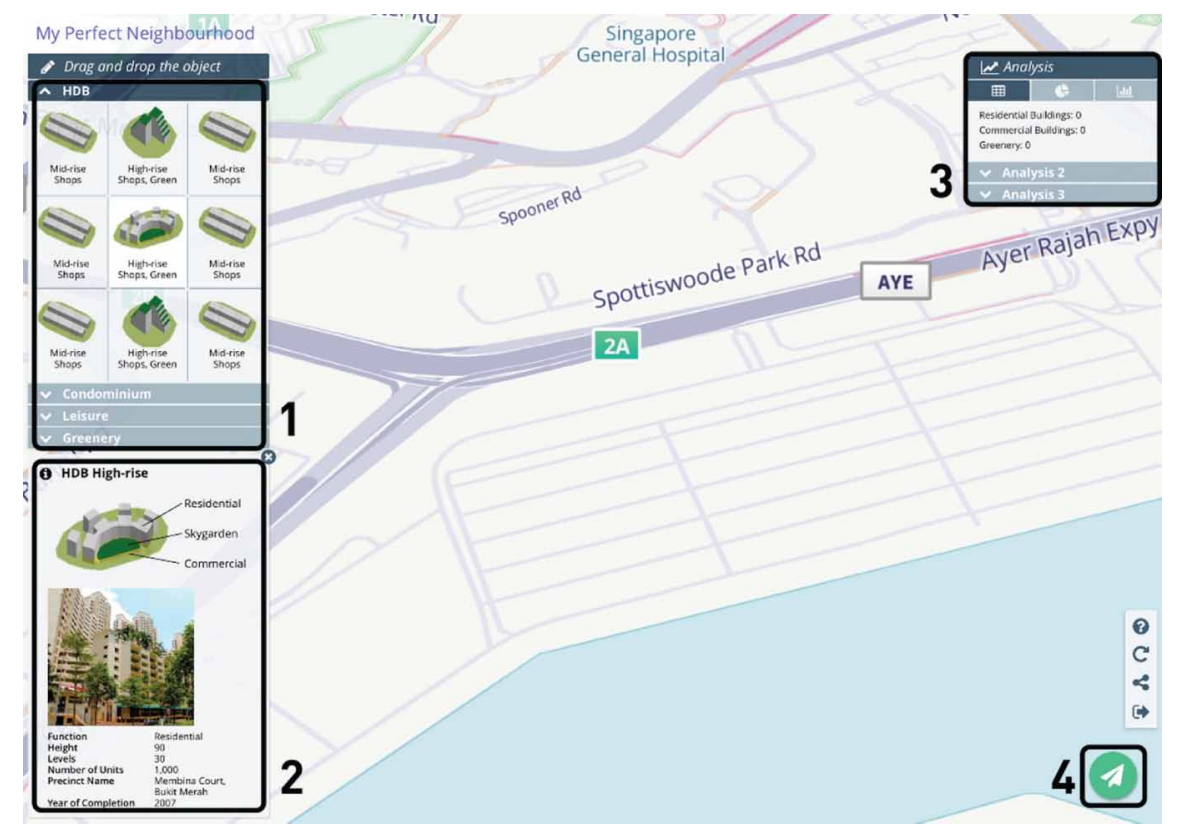

width for the elements on the left and right. This allows the main map to be viewable on all devices. On mobile phones, the object palette will be displayed as a scrollable one row element at the bottom of the screen.

This particular arrangement of the elements was based on a review of other interactive map tools. Important features that a user must see to begin their interaction are always located on the left. One reason for that is, that texts are written from left to right and top to bottom in Western cultures. The analytical information that is processed by the left side of the brain should be positioned on the opposite side of the interface. The 'submit' button is positioned where people expect the 'proceed' or 'exit' button (4) to be.

The object palette has a stronger focus on the visual representation of the objects rather than the textual description. The items are organised in clusters to help users not feel overwhelmed by the information presented. An additional feature for better readability is the highlighting of active windows. The instruction is reduced to a one-liner that by default tells the user how to add objects to the map. Objects can now be added using the 'drag and drop' function. A pop-up appears once the object is selected on the map or on the palette. Instead of deleting an object by clicking on a central button, the user can now click on a little ' $\mathrm{x}$ ' button appearing on the top right of each selected object. An arrow on the bottom right allows a small stepwise rotation on both sides (of around $15^{\circ}$ ). This removes the need for the right-click function to be used.

The analysis element is an additional feature of the new layout. With the same philosophy of presenting information in smaller pieces, users can manually switch between different analysis tools and see real-time changes if they revise their design. The new feature enhances the tool to become a platform that can summarise the designs in real-time, instead of presenting static data only. Users can therefore gain a better understanding of the metadata of their designs and can modify their designs to meet their own preferences.

The button bar on the bottom right has been resized, except for the submit button. The submit button is also now a paper plane icon instead of a floppy disk icon, which helps users to quickly recognise its function, as users would also recognise the icon from standard mailing programs. 


\section{CONCLUSION}

In this article, we described the implementation of a participatory design study in a real-life scenario that was conducted with a digital design tool. Our objective was to find out how to encourage citizens to use online participation tools and identify the level of willingness for citizens to use such tools. We also collected user feedback from the public to improve the tool's user interface and explained which elements and functions are critical to ensure an intuitive design.

The tool and the participatory approach were generally received positively and motivated participants to think about urban planning. There are no significant obstacles preventing a user's digital interaction with 3D models, although most participants found it easier to understand the interface's function when staff were on-site to explain it. As such it is necessary to redesign the user interface to adapt to the user's habits, keep information concise, and guide the user's attention towards completing the study. One other solution is to carry out workshops with the online participatory study as an additional component. Our results show that it is still easier to engage a large number of people through face-to-face engagement. One challenge of an online-only participation project is that the user interface must be of a high quality, and that the project topic must be attractive and relevant to the intended target group.

In this final section, we want to use our results and the experience gained from this study to formulate a set of guidelines for designing websites for citizen participation, and interactive participatory design tools:

1. Study - Collaboration with citizens: Know the social and political culture you are working in;

2. Study - Collaborate with local authorities: Only that can show real-life effects. Alternatively, look for support from local interest group or other partners. Make the results of your results public if possible;

3. Website: Come straight to the point. Though the information might be necessary to show from a research perspective, you should integrate it in the study intelligently;

4. Website: Keeping the attention of the users has the highest priority;

5. Tool interface: Review other tools and anticipate the experience of users (icons, organisation of elements);

6. Tool interface: Structure information - visually. Users don't need all information at one point;

7. Tool interface: To inform people, you must reduce the information to the essential one.

In summary, we have gained several insights from this study. As our research interests also included understanding how to conduct a participatory study in urban design, it was clear that our study had to be realised in a non-experimental environment. However, such real-life experiments require a lot of coordination and expertise in many different fields. We would therefore recommend that other researchers think of a simpler study design that is specific to the research question. To launch new technologies on the market requires that such technologies are also commercially viable. Applications for research projects are often not in the final stage of product development; as such, it can make sense to keep the study within the experimental realm. As to the digital interface, user feedback helps developers troubleshoot issues experienced when using the tool. It is crucial to remember that the users of such tools are non-experts who voluntarily give time to completing the participation project. They will gradually lose interest in the study if they get the impression that they are not able to manage the task. One way of mitigating this would be to structure the information carefully and deliver the relevant pieces of information at the right time.

One limitation of this study is that it was conducted with mainly young participants who had above-average educational qualifications. Future research should therefore focus on the degree of acceptance for the use of digital participatory tools in other demographic groups, such as the elderly. 
Another interesting area of inquiry would be to study the implementation of such participatory tools in the urban planning process. Urban governance was not the focus of this article by it plays an important part in achieving widespread acceptance of such new approaches of engaging citizens.

\section{ACKNOWLEDGMENT}

The research was conducted at the Future Cities Laboratory at the Singapore-ETH Centre, which was established collaboratively between ETH Zurich and Singapore's National Research Foundation (FI 370074016) under its Campus for Research Excellence and Technological Enterprise programme.

\section{Declaration of Interest}

We have no conflict of interest to declare. 


\section{REFERENCES}

Arnstein, S. R. (1969). A ladder of citizen participation. Journal of the American Institute of Planners, 35(4), 216-224. doi:10.1080/01944366908977225

Arthur, C. (2006, July 20). What is the $1 \%$ rule? The Guardian.

Brown, G. (2015). Engaging the wisdom of crowds and public judgement for land use planning using public participation geographic information systems. Australian Plants, 52(3), 199-209. doi:10.1080/07293682.201 5.1034147

Cilliers, E. J., Diemont, E., Stobbelaar, D. J., \& Timmermans, W. (2011). Sustainable green urban planning: The workbench spatial quality method. Journal of Place Management and Development, 4(2), $214-224$. doi:10.1108/17538331111153197

Ginige, A., \& Murugesan, S. (2001). Web engineering: An introduction. IEEE MultiMedia, 8(1), 14-18. doi:10.1109/93.923949

Hasler, S., Chenal, J., \& Soutter, M. (2017). Digital Tools as a Means to Foster Inclusive, Data-informed Urban Planning. Civil Engineering and Architecture, 5.

Heuser, T., Post, A., \& Richter, S. (2018). Bürgerschaftliche Mitverantwortung - Fünf Grundsätze Bürgerschaftlicher Mitverantwortung. Retrieved from https:/www.stiftungzukunftberlin.eu/die-stiftung/ buergerschaftliche-mitverantwortung/

Hussey, A. (2000). Formal object-oriented user-interface design. In Proceedings 2000 Australian Software Engineering Conference (pp. 129-137). IEEE. doi:10.1109/ASWEC.2000.844570

Kahila-Tani, M. (2013). SoftGIS development process as a trading zone: Challenges in implementing a participatory planning support system. In Urban planning as a trading zone (pp. 75-93). Dordrecht: Springer. doi:10.1007/978-94-007-5854-4_5

Kahila-Tani, M., Broberg, A., Kyttä, M., \& Tyger, T. (2016). Let the citizens map_public participation GIS as a planning support system in the Helsinki master plan process. Planning Practice and Research, 31(2), $195-214$. doi:10.1080/02697459.2015.1104203

Karvonen, K. (2000). The beauty of simplicity. In Proceedings on the 2000 conference on Universal Usability (pp. 85-90). ACM. doi:10.1145/355460.355478

Kersten, W. C., Crul, M. R. M., Geelen, D. V., Meijer, S. A., \& Franken, V. (2015). Engaging beneficiaries of sustainable renovation-exploration of design-led participatory approaches. Journal of Cleaner Production, 106, 690-699. doi:10.1016/j.jclepro.2014.07.060

Kleinhans, R., Van Ham, M., \& Evans-Cowley, J. (2015). Using Social Media and Mobile Technologies to Foster Engagement and Self-Organization in Participatory Urban Planning and Neighbourhood Governance. Planning Practice and Research, 30(3), 237-247. doi:10.1080/02697459.2015.1051320

Lee, T. Y., Smith, A., Seppi, K., Elmqvist, N., Boyd-Graber, J., \& Findlater, L. (2017). The human touch: How non-expert users perceive, interpret, and fix topic models. International Journal of Human-Computer Studies, 105, 28-42. doi:10.1016/j.ijhcs.2017.03.007

Lee, W., \& Benbasat, I. (2003). Designing an electronic commerce interface: Attention and product memory as elicited by web design. Electronic Commerce Research and Applications, 2(3), 240-253. doi:10.1016/S15674223(03)00026-7

Levin, I. P., Schneider, S. L., \& Gaeth, G. J. (1998). All frames are not created equal: A typology and critical analysis of framing effects. Organizational Behavior and Human Decision Processes, 76(2), $149-188$. doi:10.1006/obhd.1998.2804 PMID:9831520

Linders, D. (2012). From e-government to we-government: Defining a typology for citizen coproduction in the age of social media. Government Information Quarterly, 29(4), 446-454. doi:10.1016/j.giq.2012.06.003

Lindgaard, G., Fernandes, G., Dudek, C., \& Brown, J. (2006). Attention web designers: You have 50 milliseconds to make a good first impression! Behaviour \& Information Technology, 25(2), $115-126$. doi:10.1080/01449290500330448 
Lukyanenko, R., Parsons, J., Wiersma, Y. F., Sieber, R., \& Maddah, M. (2016). Participatory Design for Usergenerated Content: Understanding the challenges and moving forward. Scandinavian Journal of Information Systems, 28(1), 2.

McKay, E. N. (2013). UI is communication: How to design intuitive, user centered interfaces by focusing on effective communication. Newnes.

Mueller, J., Lu, H., Chirkin, A., Klein, B., \& Schmitt, G. (2018). Citizen Design Science: A strategy for crowdcreative urban design. Cities (London, England), 72, 181-188. doi:10.1016/j.cities.2017.08.018

Münster, S., Georgi, C., Heijne, K., Klamert, K., Noennig, J. R., Pump, M., \& van der Meer, H. et al. (2017). How to involve inhabitants in urban design planning by using digital tools? An overview on a state of the art, key challenges and promising approaches. Procedia Computer Science, 112, 2391-2405. doi:10.1016/j. procs.2017.08.102

Nanz, P., \& Leggewie, C. (2016). Die Konsultative: Mehr Demokratie durch Bürgerbeteiligung. Verlag Klaus Wagenbach.

Parush, A., Shwarts, Y., Shtub, A., \& Chandra, M. J. (2005). The impact of visual layout factors on performance in Web pages: A cross-language study. Human Factors, 47(1), 141-157. doi:10.1518/0018720053653785 PMID:15960093

Roth, R. E., Ross, K. S., \& MacEachren, A. M. (2015). User-centered design for interactive maps: A case study in crime analysis. ISPRS International Journal of Geo-Information, 4(1), 262-301. doi:10.3390/ijgi4010262

Rowe, G., \& Frewer, L. J. (2000). Public participation methods: A framework for evaluation. Science, Technology \& Human Values, 25(1), 3-29. doi:10.1177/016224390002500101

Shamat, N. A., Sulaiman, S., \& Sinpang, J. S. (2017). A Systematic Literature Review on User Interface Design for Web Applications. Journal of Telecommunication Electronic and Computer Engineering, 9(3-4), 57-61.

Stelzle, B., \& Noennig, J. R. (2017). A Database for Participation Methods in Urban Development. Procedia Computer Science, 112, 2416-2425. doi:10.1016/j.procs.2017.08.173

Terry, M., \& Mynatt, E. D. (2002). Recognizing creative needs in user interface design. In Proceedings of the 4th conference on Creativity \& cognition (pp. 38-44). ACM. doi:10.1145/581710.581718

Urban Redevelopment Authority. (2014). Central Area - Greater Southern Waterfront. Accessed from https:// www.ura.gov.sg/Corporate/Planning/Draft-Master-Plan-19/Urban-Transformations/Greater-Southern-Waterfront retrieved on $11 / 04 / 2019$

Vincent, K., Roth, R. E., Moore, S. A., Huang, Q., Lally, N., Sack, C. M., ... \& Rosenfeld, H. (2018). Improving spatial decision making using interactive maps: An empirical study on interface complexity and decision complexity in the North American hazardous waste trade. Environment and Planning B: Urban Analytics and City Science, 2399808318764122.

Wates, N. (2014). The Community Planning Handbook: How people can shape their cities, towns \& villages in any part of the world. Routledge. doi:10.4324/9781315848716

Wenting, L., Tian, S., Hong, Z., \& Ying, Y. (2010, November). Interface design in the ship navigation information system. In Proceedings of the 2010 IEEE 11th International Conference on Computer-Aided Industrial Design \& Conceptual Design (Vol. 1, pp. 395-400). IEEE. doi:10.1109/CAIDCD.2010.5681326

Wilson, A., Tewdwr-Jones, M., \& Comber, R. (2017). Urban planning, public participation and digital technology: App development as a method of generating citizen involvement in local planning processes. Environment and Planning B: Urban Analytics and City Science. 
Johannes Mueller is a Post-Doctoral Researcher at ETH's Future Cities Laboratory in Singapore. Within the Big Data Informed Urban Design and Governance project, he works on Citizen Design Science, a recently developed strategy for crowd-creative citizen participation in urban planning. He is a mathematician and statistician by training, and analysed innovation transportation systems during his time as PhD student at the Bundeswehr University in Munich.

Shiho Asada is a designer working on user experience (UX) and user interface (UI) with a focus on data visualization. Currently she works at Designit in Oslo and previously served as a UX/UI designer at Singapore-ETH Centre. Since she started studying Information Design in the UK, she has been strongly interested in UX/UI, data visualization and interaction design. She aims to create intuitive and minimalistic designs with an eye for typographic detail.

Ludovica Tomarchio is a PhD candidate at the Singapore University of Technology (SUTD) and Design and researcher in the Big Data Informed Urban Design and Governance project. Her research focusses on the use of social media and the production of art in urban spaces in Singapore. Her work explores the convergence of the Smart/Responsive Cities and the Creative Cities discourses as new urban planning paradigm. Her student mentees at SUTD were awarded the best project award in 2018. Ludovica earned her master degree in architecture at the Politecnico di Milano, Italy, in 2013 with a thesis on digital technologies enhancing livability of public realms in historic centres. 